\title{
Aspecte Ale sacrului și profanului în TOPONIMIA URBANĂ TRANSILVĂNEANĂ
}

\author{
Oliviu Felecan \\ Universitatea Tehnică din Cluj-Napoca, \\ Centrul Universitar Nord Baia Mare, România
}

\begin{abstract}
Sacred and profane aspects in Transylvanian urban toponymy
Abstract: In some of my previous studies (Felecan 2013a, Felecan 2013b; Felecan 2015; Felecan 2016; Felecan 2017), I approached Romanian oikonymy and hodonymy from a historical, social, and ethnic perspective. This paper will take into consideration religious and secular aspects mirrored by names of settlements and streets in Transylvania. In the past century, this area has witnessed several institutionalized processes of name change, especially due to political reasons.
\end{abstract}

Keywords: oikonyms, hodonyms, sacred, profane.

\section{Considerații introductive}

În context european, numele de localități cu o conotație religioasă sunt numeroase și datează din Evul Mediu, când creștinismul era omniprezent și avea o influență covârșitoare asupra societății, atât în spațiul romanic, cât și în cel germanic, unde catolicismul era atotputernic. Exemplele abundă în majoritatea limbilor (v. Toma in Sala 1989: 143) și au în vedere aspecte diverse, dintre care amintim:

- păstrarea memoriei unor martiri: cat. Martorell, fr. Martrois, it. Martirano, sp. Los Mártires;

- au la bază numele patronului bisericii locale: cat. Sant Andreu, Sant Nicolau; engl. St. Alban, St. David's; fr. Saint-Martin, Saint Pierre; germ. Sankt Augustin, Sankt Gallen; it. San Matteo, San Pietro; oc. Saint Tropez; pg. São Pedro, São Rafael; sp. San Juan, San Sebastian;

- provin din apelative care denumesc instituții și funcții clericale: fr. Bazailles, Bazoches; rom. Bisericani; sp., pg. Baselgas< lat. basilica; it. Chiesa, Chiesuola; fr. Glisolles, Neuvéglise; sp. Airexe, Grixa< lat. ecclesia; fr. Faremoutiers, Montreuil; it. Monastirolo; rom. Mănăstirea; sp., pg. Mosteiro; sp. Fraile, rom. Frata< lat. frater; sp. Bisbal, Eidobispo< lat. episcopus;

- nume biblice: fr. Bithaine; germ. Bethausen/ Bethlenhaas; magh. Bethlenháza; rom. Beclean (<magh. Bethlen); sp. Belén (<Bethlehem).

Răspândirea și frecvența unor astfel de nume depind de tradițiile vieții ecleziastice din fiecare teritoriu, forma diferind de la o limbă la alta în funcție de legile fonetice care au acționat asupra cuvintelor în trecerea acestora din latină în limba romanică 
respectivă sau în funcție de stratul cultural predominant. În spațiul românesc, oiconimele cu origine hagionimică sunt mult mai numeroase în Transilvania și Banat, datorită tradiției religioase apusene ${ }^{1}$, pe de o parte, și proprietăților deținute de clerici, episcopi și mănăstiri, pe de altă parte (v. Goicu 1999: 146-183). Într-un studiu recent precizam că „the structure of certain names of settlements can allow us to distinguish a certain historical phase, and even a linguistic and cultural phase, which can be related to the ever-increasing influence of the peoples that, in certain ages, established a direct contact with the Romanian people, or ruled over parts of Romanian lands. In this respect, we adduce the examples of the lexemes used for the word sfânt 'saint': sânt (sân, sâm) (inherited from Latin sanctus), sfânt (from Slavic sventŭ), Hungarian szent, German Sankt. Besides these forms, one can also mention the names of saints, which appear in inherited variants, in elements of Slavic origin, or in Hungarian and German (Nicoară / Nicola(i)e / Miklós; Sângeorz / Szent-György / Sankt-Georgen, and so on)" (Felecan O., Felecan N. 2014: 106). În această perspectivă, se poate afirma că, la nivelul numelor de localități, trimiterile la sacru² sunt evidente, când oiconimul este transparent și pentru profani, sau opace, atunci când avem forme moștenite din latină sau împrumutate din limbile cu care româna a intrat în contact. Citirea corectă a acestora presupune deținerea și actualizarea cunoștințelor de istoria limbii române, de limbă maghiară şi germană.

\section{Oiconime opace din punct de vedere religios}

Evoluția de la latină la română presupune, ca în celelalte limbi romanice, mai multe schimbări fonetice și grafice, care îndepărtează forma actuală de etimonul antic sau medieval. Erodării în timp a formelor vechi i se adaugă faptul că, în Transilvania, multe cuvinte latinești desemnând funcții ecleziastice, forme de organizare bisericească, trimiteri la locuri sacre au fost maghiarizate sau germanizate ${ }^{3}$, ceea ce a condus la apariția unor variante multiple în limba noastră (cf. ELR 2001: 249-250), răspândite în toate județele din spațiul intracarpatic ${ }^{4}$ :

- Apadia (CS), Apahida (magh. Apahida< apát + hid „pod”, lat. Pons Abbatis, CJ), Apalina (MS), Apateu (AR, BH, SM), Apața (germ. Geist, magh. Apáca, lat. Monachalis, $\mathrm{BV})^{5}$;

1 Situația din Moldova și din Muntenia este similară cu cea din alte țări ortodoxe (Bulgaria, Rusia, Serbia, Ucraina), unde tradiția bizantină face ca numărul toponimelor cu origine religioasă să fie mai redus (v. ELR 2001: 249).

2 Vezi taxonomia propusă sacrului de către Daiana Felecan 2017: 20.

3 Simona Goicu (1999: 147) observă că „odată cu trecerea Ungariei la catolicism, s-a adoptat și o terminologie creștină de origine latină, care a lăsat urme în toponimia din Transilvania și Banat. Ca urmare, au pătruns în sistemul numelor de localități din aceste provincii o serie de termeni creștini de origine latină, prin intermediul unor limbi nelatine, maghiara și germana”.

$4 \mathrm{Nu}$ am dat formele atestate în documentele istorice (sec. XI-XIX); pentru acestea, v. Suciu 1967, 1968.

5 Din lat. abbas a apărut abbatia, care se continuă în fr. abbaye, it. badia, sp., pg. abadia. 
- Atea (magh. Atya, SM), Ateaș (magh. Atyás, Biharatyás, BH), Atia (magh. Atyha, HR) < magh. Atya „părinte”, utilizat în context monahal;

-Bărăteaz (rom. Călugăruș, germ. Baratzhausen, magh. Baraczháza, TM) ${ }^{6}$, Bratca (magh. Barátka, BH), Brateiu (sas. Pretoa, Preta(i), Pretâ, ger. Pretai, Bretai, Breitau, Pretau, magh. Baráthely, Paratéj, SB), Brateș (magh. Barátos, CV) „frate, monah” (< sl. brat "frate", care se regăsește și în antroponime $)^{7}$;

- Beclean (magh., germ. Bethlen, BN; sas. Bethlehem, germ. Betlen, Betlehem, magh. (Fogaras betlen, BV; magh. (Székely betlenfalva, HR); Bethausen (germ. Bethlenhaas, magh. Bethlenháza, TM) < magh. Bethlen $<$ Bethlehem;

- Căpâlna (germ. Kapellendorf, Kapolna, magh. Sebeskápolna, (Alsó) kápolna, $\mathrm{AB}, \mathrm{SJ})$, Copalnic (-Mănăștur) (magh. Kápolnokmonostar, $\mathrm{MM})<$ magh. kápolna (pl. kápolnok) „capelă” < lat. med. capella;

- Coplean (magh. Kaplyon, CJ) < magh. káplán „preot de casă sau de curte” < lat. capellanus;

- Căptălan (magh. Maroskáptalan, AB) < magh. káptalan „totalitatea consilierilor și a canonicilor unei episcopii" < lat. capitulum;

- Coșteiu (TM), Coștiui (MM) < magh. kastély< germ. Kastel< lat. castellum;

- Cherestur (magh. Pusztakeresztúr, TM) ${ }^{8}$, Cristiș (magh. Keresztes, germ. Kreuzfeld "Câmpul Cruciaților”, CJ) ${ }^{9}$, Cristolț (magh. Nagy Kerestolcz, SJ), Cristur (magh. Csernakeresztur, HD), Cristur-Șieu (sas. Eberscht-Kreiz, germ. (Ober kreuz, magh. Bethlenkeresztúr, Sajókeresztúr, BN) < magh. kereszt „cruce”; Criț (sas. (Detsch) krets, germ. Kreuzdorf, (Deutsch) Kreuz „Cruce”, magh. Szászkeresztúr „Cristuru Săsesc”, $\mathrm{BV})<$ germ. med. (frizonă) Kriuze;

- Fileghihaz (magh. Biharfélegyháza, BH, azi Roșiori), Firiteaz (AR) < au în componență magh. Egyház „sfântlăcaș, biserică" ${ }^{10} ;$ Viscri (sas. Weiskirich, Veiskirix, Veeskirx, germ. (Deutsch-)Weißkirch, magh. (Szász) fehéregyháza, „Biserica Albă (Săsească)”, BV); Chirpăr (germ. Kirchberg, „Dealul Bisericii”, magh. Kürpöd, Körpöd, SB); Nocrich (sas. Löschkirk, Laeschkirik, Leškirich, germ. Leschkirch, Löschkirch „Biserica nouă”, magh. Újegyház, SB); Hărănglab (magh. Harangláb „Piciorul clopotului, Clopotniță construită pe un picior de lemn”, germ. Glockendorf, Herenglab „Satul clopotului”, MS);

- Mănăștur (magh. Monostor < lat. monasterium, CJ, MM), Cloașterf(sas. Klosderf, Kluisderf, Klîsderf, Klîstref, Kliusderf „satul mănăstirii”, germ. Klos(s)dorf, Nickelsdorf, magh. Miklóstelke, MS);

6 Potrivit lui Frățilă (2011: 412), etimologia trebuie căutată în magh. Barátháza< barát „călugăr” + ház „așezare, casă”.

7 Sub forma Bărăție se întâlnește și în celelalte regiuni ale României, cu sensul „locaș de cult catolic".

8 Oiconimul bănățean de origine magh. Keresztúr < magh. kereszt „cruce” + úr „Domn(ului Isus) (cf. Frățilă 2011: 415) s-ar putea traduce „Sfânta Cruce”.

9 În prezent, fostul sat a fost inclus în municipiul Turda, sub numele de cartierul Oprișani.

10 „În română, uneori, finala -haz(a) a devenit -(e)az: cf. Bărăteaz, dar și -az, cf. Săcălaz” (Frățilă 2011: 414). 
- Piscopia (în prezent Episcopia Bihorului; magh. Biharpüspöki/(Várad)püspöki, BH), Pişchia (germ. Bruckenau, magh. Hidasliget, TM) < magh. Pysky< magh. püspöki „episcopie”;

- Proștea Mare (azi Târnava, sas. Griuszpriustref, germ. Gross-Probstdorf, Groß(-) Probstdorf „Satul mare al prepozitului”, magh. (Nagy)ekemezö, Prépostfalva, SB), Proștea Mică (azi Târnăvioara, sas. Klipriusterf, germ. Kleinprobstdorf „Satul mic al prepozitului”, magh. Kisekemezö, SB) < magh. prépost „superiorul unui preot catolic” < lat. med. praepositus „,inainte-stătător”;

- Remetea (magh. Magyarremete, BH; magh. Gyergyóremete, „Remetea Giurgeului”, HR), Remetea Chioarului (magh. Kövárremete, MM), Remetea Mare (germ. Grossremete, magh. Temesremete sau Oláhremete, „Remetea Română”, TM), Remetea Oaşului (magh. Köszegremete, SM), Remeți (magh. Pálosremete, MM), Rîmetea $(\mathrm{AB})<$ magh. remete „pustnic, sihastru, călugăr" < lat. eremita.

Multitudinea și varietatea oiconimelor cu conotație religioasă atestă poziţia dominantă a bisericii din Transilvania, atât în varianta sa bizantino-ortodoxă, cât mai ales în cea catolică, deoarece majoritatea populației aflate în dependență feudală aparținea bisericilor și mănăstirilor ${ }^{11}$. Din multitudinea ordinelor monahale prezente în Europa Centrală și susținute de regalitatea maghiară să se împământenească în Transilvania, au lăsat mărturii onomastice benedictinii ${ }^{12}$, cistercienii, dominicanii, franciscanii. Totuşi, în timp, unele localităţi cu astfel de nume au dispărut odată cu bisericile, apărând în locul lor aşezări rurale „botezate” după sfinții care au oferit hramul bisericilor. Acestea au rezistat mai bine în peisajul oiconimic transilvan, întrucât, pe de o parte, erau accesibile tuturor etniilor, inclusiv celei române, majoritare, iar, pe de altă parte, numele sfinților (Maria, cei doisprezece Apostoli etc.) erau compatibile cu sfera spiritual-culturală a creștinismului de rit oriental. Așa cum observă Ion Toma (ELR 2001: 250), „cel mai frecvent apar numele unor sfinți care nu sunt specifici maghiarilor (Nicolae, Gheorghe, Mihai, Petru, Ioan, Andrei, Dumitru, Cozma, Damian, Ilie), ci mai degrabă ariei de cultură bizantino-slavă, ceea ce poate conduce la presupunerea că, în momentul punerii numelui, bisericile de rit ortodox au oferit hramul, iar oficialităţile modelul catolic de numire a localității în funcție de biserica de pe teritoriul său”.

\section{Oiconime transparente din punct de vedere religios}

În comparație cu numele de localități opacizate din perspectivă creștină,

11 Andrea Bőlcskei constată că, „in a feudal society - which connected authority to the owner ship of landed property - the medieval Hungarian Church - whilst establishing the economic background to support its ambitions to act as a spiritual leader as well as a mighty political power in the country - wanted to emphasize its role as a proprietar also in settlement names" (2013: 251).

12 De ex. Benediuc (azi Mănăstirea, magh. Szent Benedek, CJ) și Benesat (magh. Benedekfalva, SJ) < numele ordinului monastic benedictin, care a avut mănăstiri în Evul Mediu în locurile respective. O mănăstire cisterciană a fost fondată în Cârța (sas. Kierz, Kierts, germ. Kerz, „Candelă”, „Lumânare”, magh. $\operatorname{Kerc}(z), \mathrm{SB})$. 
oiconimele care au o structură transparentă sunt mult mai numeroase și, în Transilvania, prezintă asemănări cu cele din Ungaria. Andrea Bőlcskei (2013: 246) observă „two essentially relevant name types: (i) settlement names providing information in connection with the ecclesiastical building of the habitation (i.e. name forms referring to ecclesiastical buildings, their parts as well as the patron saint to whom the church was dedicated); and (ii) settlement names stressing the role of the medieval Church as a feudal land owner (i.e. name forms referring to church men and ecclesiastical bodies)"13. Numele celor mai populari sfinți, reflectate în oiconimele transilvănene, sunt Sf. Nicolae, Sf. Gheorghe, Sf. Mihail, Sf. Petru și Sf. Ioan. Denumirile localităților se explică fie prin trimitere la numele sfântului protector, fie la acela al unor mănăstiri, care au reprezentat repere puternice în zonele respective.

Din punct de vedere lingvistic, se observă o diferență terminologică în transpunerea latinescului sanctus în limba română. Dacă numele localităților din spațiul extracarpatic au în componență termenul de origine slavă sfânt, în Ardeal se întâlnește mult mai des lexemul moștenit sân $(t)$, ceea ce arată, pe de o parte, profunzimea romanizării teritoriului, iar, pe de altă parte, influența religioasă apuseană. În continuare, urmând clasificarea propusă în studiul Cultural and linguistic layers embedded in Romanian oikonyms derived from hagionyms (Felecan O. \& Felecan N. 2014: 92-97), vom inventaria câteva dintre denumirile localităților care provin de la numele sfinților:

- cu lexemul sfânt(ă): Sfânta Elena (ceh. Svatá Helena, CS), Sfânta Elisabeta (ceh. Svatá Alžběta, CS) ${ }^{14}$, Sfântu Gheorghe (magh. Sepsiszentgyörgy, CV, MS), Șieu-Sfântu (magh. (Sajó)szentandrás, BN);

- cu elementul sânt (sân, sâm), urmat sau nu de un apelativ: Sân(t)andrei (BH, HD, MS, TM), Sâncrai(u) (magh. Enyedszentkirály „Sâncraiu de Aiud”, germ. Königsdorf „Satul Regelui”, AB; magh. Kalotaszentkirály „Sâncraiu Călatei”, CJ; magh. (Sepsi)szentkirály, CV; magh. Székelyszentkirály, HR; HD) ${ }^{15}$, Sândominic (magh. Csíkszentdomokos, HR), Sîngeorgiu de Pădure (magh. Erdőszentgyörgy, MS), SângeorzBăi (germ. Sankt Georgen, magh. Oláhszentgyörgy, Naszódszentgyörgy, BN), Sâniacob (germ. Jakobsdorf (bei Bistritz), magh. (Szász)szentjakab, BN; magh. Marosszentjakab, MS), Sânmartin (AR, BH, CJ, HR), Sânmihaiu de Câmpie (BN), Sânnicoară (BN, CJ), Sânnicolau de Munte (BH), Sânmiclăuș (AB, SM), Sânpaul (AR, CJ, HR, MS), Sânpetru (BV, HD), Sânsimion (HR, MS), Sânta Maria (SJ), Sântămăria de Piatră (HD),

13 Tot pentru regatul maghiar, András Mező (1996: 23-24; 1997: 245), bazându-se pe studiul numelor de localități provenite de la denumirile bisericilor (7\% dintr-un total de 20000), „identifies four types of Hungarian ecclesiastical settlement names: (i) names referring to an ecclesiastical building or its parts; (ii) names referring to the patron saint to whom the church was dedicated; (iii) names referring to a churchman; and (iv) names referring to an ecclesiastical body" (apud Bölcskei 2013: 246).

14 Amândouă localitățile au fost întemeiate de coloniști cehi în prima jumătate a sec. al XIX-lea, însă a doua nu mai este locuită.

15 Oiconimul, sub diferite variante, face trimitere la Sf. Rege Ștefan (magh. Szent István Király), care a creștinat ungurii în jurul anului 1000. 
Sântămărie (AB), Sântana (AR), Sântana de Mureș (MS), Sântejude ${ }^{16}$ (CJ), Sântimbru (AB, HR), Sântimreu (BH), Sântioana (BN, CJ, MS), Sântion (BH), Sânvăsii (MS), Sânzieni $(\mathrm{CV})^{17}$;

- numele sfântului poate fi neînsoțit de apelativ: Benic (<St. Benedict; HD), Catalina (magh. Szentkatolna, CV) / Cătălina (<St. Katherina,magh. Szentkatolna, CJ, MM), Dămăcușeni (<Dămăcuș = magh. Domokoș: Szent Domokos „St. Dominic”, $\mathrm{MM})^{18}$, Iacobeni (germ. Jakobsdorf, magh. Jakabfalva, SB).

În cazul ultimei categorii, apar sufixele -eni (care arată originea locală) și -ești (patronimic), răspândite în tot teritoriul românesc, nu doar în Transilvania. Dovada că avem a face cu oiconime de factură religioasă și nu cu denumiri provenite de la așezarea geografică sau de la întemeietorul satului o dau formele maghiare, având o evidență hagionimică mult mai pronunțată. „The choice of hagionyms to designate human settlements psychologically corresponds to placing those settlements under the protection of saints so as to keep them safe from danger and disaster" (Felecan O. \& Felecan N. 2013: 97).

Tot în categoria oiconimelor transparente din punct de vedere religios sunt încadrabile denumirile unor localități formate de la termeni religioși românești: Bisericani (< biserică; magh. Székelyszentlélek, HR), Călugări (<călugăr; BH), Chilia (<chilie; SM), Clopotiva (<clopot; HD), Cruceni (magh. Keresztes, germ. Kreuzstätten, AR), Mănăstirea (Benediug(u Dejului), magh. Szentbenedek, CJ; MM); Popeni (< popă; în trecut Poptelec, SJ) ${ }^{19}$, Preoteasa (magh. Paptel(e)ke, SJ).

\section{Oiconime laice}

În comparație cu numărul oiconimelor de factură religioasă, cele laice sunt mult mai numeroase, având o răspândire pe întreg teritoriul Transilvaniei. Majoritatea „sunt motivate originar, fie direct, prin descrierea fizică a locului în care sunt așezate, fie indirect, prin raportarea la topice alăturate sau la aspecte sociale, inclusiv la oamenii care au locuit în aceste așezări” (ELR 2001: 392-393). Sfera oiconimelor profane este vastă, prin urmare, în cele ce urmează, ne vom concentra atenția asupra a două categorii extrase din mediul online ${ }^{20}$, ale căror denumiri conotează sensuri ce pot fi asociate, la o primă lectură, cu ideea de vulgaritate, obscenitate. Impuse de autoritățile administra-

16 Sântejude este „o adaptare românească a magh. Szent Egyed (<lat. SanctusEgidius)” (Goicu, 1999: 144).

17 Unele sate au păstrat până astăzi denumirea maghiară, dar românizată: Sânianoș (cătun înglobat în orașul Carei, SM), Sânmiclăuș (magh. Szentmiklós, AB, magh. Miklós fiind echivalent cu rom. Nicolae), Sântămaș(u).

18 Chiar dacă, aparent, oiconimul pare opac, acesta este transparent pentru maghiari, care sunt majoritari în localitatea din Țara Lăpușului.

19 Până în sec. al XVIII-lea a existat o mănăstire în localitate.

20 Amintim doar două: http://atlas-geografic.net/cele-mai-ciudate-nume-de-localitati-din-romania/; http://adevarul.ro/news/societate/cele-mai-amuzante-nume-localitatiromania-celebra-cuca-macaii-gauricea-buda-pacalesti-satul-s-a-nascut-mai-glumet-roman1_54c3921f448e03c0fde9fee8/index.html 
tive, (re)denumirea acestora reprezintă „strategii ale puterii exercitate pentru controlarea spațiului public, social și politic” (Felecan 2016: 440).

4.1. Din prima categorie, fac parte nume care, din punct de vedere etimologic (prin limba maghiară, germană etc.) sau prin configurația reliefului din zona respectivă, nu au nicio conotație vulgară, deși percepția colectivă, profană, lasă să se întrevadă anumite trimiteri licențioase:

- împrumuturi directe sau prin intermediul unor toponime din limbile minorităților etnice din Transilvania: Băgău (magh. Magyarbagó, AB) < pârâul omonim; Beliș (magh. Béles, CJ) < râul omonim, care se varsă în lacul de acumulare BelișFântânele; Curtici (magh. Kürtös „gornist”, AR) ${ }^{21}$; Labașinț (AR); Spermezeu (magh. Ispánmező „Câmpul vătafului”, BN) < toponim maghiar;

- diminutive: Căpruța (magh. Kapruca, AR); Sânișor (MS);

- derivate cu sufixe: Cocoșești $(\mathrm{AB})<$ probabil de la întemeietorul numit Cocoș; Fundătura (CJ, MS) <înfunda + suf. -ătură22 ; Păcălești $(\mathrm{BH})<$ de la numele unui localnic ${ }^{23}$;

- compuse analitice, formate prin adăugarea la forma de bază a unor determinanți cu rol distinctiv:

a) subst. + subst. în G: Dosu Napului $(\mathrm{CJ})<$ pârâul omonim;

b) subst. + prep. + adv.: Cioara de Sus (AB), Crăciunelu de Jos (AB), Veneția de Jos (magh. Alsóvenice, germ. Untervenitze, $\mathrm{BV}$ ) < râul Venecioara, în albia căruia se găsesc pietre vineții;

- deonime: Iapa (MM) < top. Valea Iepei;

- adjective: Larga $(\mathrm{MM})<$ top. Valea Largă.

În fapt, numele însele nu trimit la un referent tabu, percepția unora dintre vorbitori fiind cea care generează chei de lectură mai puțin „canonice”. Majoritatea localităților cu denumiri resimţite ca indecente, inestetice au fost înlocuite în perioada comunistă, sistematic, deoarece nu se încadrau, din punct de vedere etic și estetic, în rigorile, cerințele noii orânduiri, care se dovedea „very restrictive as regards obscene allusions and slang" (Felecan 2017: 82). Numărul unor astfel de oiconime era mult mai mic în comparație cu al celor din Moldova sau Muntenia, dar se regăsesc pe întreg cuprinsul Transilvaniei: Beleștii de Jos (azi Făgetul de Jos, AB), Beșeneu (azi Moacșa, $\mathrm{CV}$ ), Beșinău (azi Secășel, AB), Cacova (azi Livezile, AB; Fântânele, SB), Crăcești (azi Mara, MM), Flocești (azi Florești, AB) ${ }^{24}$, Flocoși (azi Izlaz, AB), Găureni (azi Văleni, AB; Alunișul, BN; Brazi, HD), Găuricea (azi Livezi, HD) ${ }^{25}$.

21 În perioada interbelică a purtat, temporar, numele Decebal.

22 Semnificația trimite la „fundul unei văi; loc înfundat între înălțimi; vale înfundată într-o pădure; depresiune”, cf. DELR 2009: 215.

23 Între 1968 și 2008 satul a fost încorporat în comuna Drăgănești, cu numele Țigănești, dar, printr-un referendum din 2007, s-a revenit la denumirea inițială, preferată de majoritatea localnicilor.

24 În acest caz s-a apelat la modificarea unei singure litere, din rațiuni eufonice, la fel ca în exemplul Fetești<Futești (IL), modificare petrecută încă în prima jumătate a sec. al XIX-lea.

25 Vechile denumiri le-am preluat din Indicatorul localităţilor din România (1974). 
Nume de localități obscene se întâlnesc în diferite spații geografice, însă acestea nu au neapărat o conotație negativă în limbile utilizate în regiunile respective: Anus (Franța), Labia (Belgia), Pula (Croația), Vagina (Rusia). Probabil aproape toate țările au oiconime ale căror sensuri trimit la realități tabuizate în limba localnicilor sau în cea a vizitatorilor: Ass (Ucraina), Bitchfield (Anglia), Condom (Franța), Corps-Nuds (Franța), Dick LickSprings (USA), Fucking (Austria), Hookersville (USA), Intercourse (USA), Pornóapáti (Ungaria), Pussy (Franța), Titty Hill (Anglia) ${ }^{26}$.

4.2. A doua categorie privește oiconimele impuse de autorități pe cale administrativă. În mare măsură, acestea sunt creații artificiale, „,care ignoră raportul de motivare dintre toponim (nume topic) și obiectul geografic denominat, în particular o așezare umană, o localitate" (Nicolae, Suditu 2008: 216). În Transilvania, după 1918, schimbările unor nume de localități au avut ca temei, în special, criteriul etnic, lucru prezentat pe larg de Felecan 2016: 442-444. După instaurarea comunismului însă, a avut loc un proces sistematic de modificare a peisajului oiconimic al țării, în relație cu ideologia noului regim. Nu vom insista asupra tuturor criteriilor postulate de puterea comunistă, prezentate pe larg în Felecan 2017: 78-87, ci vom aminti doar câteva exemple evocatoare din perspectiva dihotomiei sacru/ profan, știindu-se că biserica, în general, a fost prigonită în anii ateismului comunist. Trebuie precizat faptul că, în comparație cu celelalte regiuni românești, Transilvania a cunoscut cele mai puține schimbări oiconimice explicabile religios, probabil și datorită peisajului pluriconfesional al zonei intracarpatice. Exemple elocvente sunt Călugări >Ponoare (BH), Iad > Livezile (BN), Iuda >Viile Tecii (BN), Püspökfürdő „Băile Episcopiei” > Băile 1 Mai (BH), Sántatelek >Izvorul Trotuşului (HR). Astfel de schimbări demonstrează faptul că nomenclatura geografică devine un instrument al propagandei comuniste, folosită cu scopul de a epura tot ce nu este conform cu noua ideologie. Actul oficial susținut de autoritatea statală și de funcționarii publici nu mai ține cont de continuitatea onomastică a localităţilor, nici de realitatea sociogeografică împământenită timp de secole.

\section{Hodonime religioase / profane}

Dintre toponimele urbane, numele de străzi sunt cele mai numeroase și se bucură de transparență totală în ceea ce privește etimologia, deoarece procesul denominativ aparține autorităților și este influențat de criterii politice, sociale, etnice, culturale, economice, mai rar religioase. Din perspectivă diacronică, în spațiul transilvănean hodonimia are o vechime multiseculară, dovedită de istoria, configuraţia socioeconomică, religioasă a zonei: Str. Cetății, Str. Cojocarilor, Str. Cositorarilor, Str. Livezilor, Str. Mănăstirii, Str. Morii, Str. Scării, Str. Școlii, Str. Tăbăcarilor, Str. Tâmplarilor, Str. Târgului, Zidul Cetății ${ }^{27}$. Nomenclatura stradală medievală este dinamică, permițând reperarea locurilor, dar, în același timp, oferă „informații asupra funcționalității diferi-

\footnotetext{
26 http://www.topito.com/top-noms-ville-insolites; http://www.elistmania.com/20_ funny_town_signs/; http://joyreactor.com/post/346401 ș.a.

${ }_{27}$ Toate exemplele au fost extrase din nomenclatorul stradal al orașului Sighișoara, cea mai bine conservată cetate medievală de pe teritoriul Transilvaniei.
} 
telor spații numite; cel mai adesea aceste nume fac referire la edificii (civile, religioase, militare), grupuri sociale sau etnice, grupuri de meșteșugari și comercianți, locuri geografice (sate și orașe situate în apropiere) etc." (Nicolae, Suditu 2008: 122-123). Păstrarea unor astfel de hodonime până în zilele noastre dovedește faptul că memoria colectivă prețuiește zestrea onomastică moștenită de la înaintaşi. Patrimoniul cultural popular al numelor de străzi trebuie conservat, chiar dacă, în zilele noastre, denumirile de odinioară nu mai corespund configurației și funcționalităţii actuale a căilor de comunicație. Prin schimbarea frecventă a denumirilor stradale, se ajunge la pierderea memoriei spațiului respectiv, noul nume, atribuit de cele mai multe ori arbitrar și interesat, ascunzând populației funcțiile și identitatea locului. Procesul de reconfigurare a spațiului este consecință a schimbării ordinii politice, administrative, iar cei aflați la cârma comunității locale controlează peisajul urbanonimic și la nivelul denumirii străzilor și piețelor.

În societatea comunistă, schimbările hodonimice au avut un temei propagandistic fără echivoc și au amplificat imaginea deplinei stăpâniri asupra spațiului și timpului. Ca regulă generală, denumirile cu trimitere sacră au fost înlăturate, în acord cu politica atee promovată de stat. După evenimentele din 1989, treptat, au reapărut nume stradale cu conotație religioasă, referitoare la:

- lăcaşuri de cult, situate în general pe respectivele artere: Piața Catedralei (Arad), Str. Bisericii (Sfântu Gheorghe), Str. Bisericii Ortodoxe (Cluj), Str. Bisericii Române (Brașov), Str. Bisericii Sfântul Toma (Cluj), Str. Episcopiei (Arad), Str. Mitropoliei (Sibiu);

- nume de sfinți: Str. Sfântul Apostol Andrei (Oradea), Str. Sfântul Ioan (Braşov), Str. Sfinții apostoli Petru și Pavel (Timișoara), Str. Sfântul Nicolae (Timișoara), Str. Sfinților (Cojocna, CJ);

- obiecte de cult sau componente ale bisericilor: Piața Crucii (Timișoara), Str. Clopotului (Arad), Str. Crucii (Lipova);

- nume ale unor fețe bisericești, emblematice pentru religia majoritară (naţională sau a comunității), fie ortodoxă - Str. Mitropolit Andrei Șaguna (Alba Iulia), Str. Mitropolit Simion Ștefan (Alba Iulia) -, fie greco-catolică - Str. Cardinal Iuliu Hossu (Cluj, Mediaș, Oradea), Str. Mitropolit Alexandru Sterca-Șuluțiu (Alba Iulia)-, fie romano-catolică - Str. Episcop Marton Aron (Cluj, Miercurea-Ciuc, Târgu-Mureș), Str. Ham Janos (Satu Mare) - sau reformată: Str. Johannes Honterus (Mediaș, Sibiu), Str. Roth Ludwig Stephan (Mediaș).

În mentalitatea credincioșilor, numele religioase pot fi de bun augur pentru cei care locuiesc pe strada respectivă. Autoritățile locale promovează astfel de valori și simboluri, asigurându-și, și în acest fel, capital electoral. Totuşi, conotaţia religioasă este uneori interpretabilă sau falsă. Unele nume de străzi sunt percepute ca având conotație religioasă, deși la baza denumirii nu a stat o atare intenție denominativă. De exemplu, hodonime de tipul Ion Agârbiceanu, Timotei Cipariu (Alba Iulia), Vasile Lucaciu, Gheorghe Șincai (Baia Mare) nu fac referire la statutul sacerdotal al celor patru, ci la calitatea de scriitor (primul), erudit transilvănean, membru fondator al Academiei 
Române (al doilea), luptător pentru făurirea Marii Uniri (al treilea) și de intelectual de marcă, reprezentant al Școlii Ardelene (al patrulea).

Procentual, în peisajul urbanonimic transilvănean, denumirile stradale de factură religioasă ocupă sub 5\% din totalul hodonimelor, ceea ce confirmă caracterul laic al societății actuale, corectitudinea politică și religioasă. Uneori, pentru a nu leza anumite sensibilități ale populației, conducerea administrativă evită nume legate de sacralitate, preferându-se denumiri neutre. Unele administrații locale consideră că numele de străzi trebuie să reprezinte, în zilele noastre, mai ales memoria colectivă istorică, națională (Bd. Unirii, Str. Independenței), în detrimentul fondului popular tradițional, motivat din punctul de vedere al geografiei urbane. Numele străzilor, pe de o parte, „conservă tradiția epocilor anterioare, iar, pe de altă parte, reproduc moda nominală de la un moment dat, tributară influențelor politice, administrative, sociale sau etnice” (Felecan 2013b: 320).

\section{Considerații finale}

Sacrul și profanul coexistă în urbanonimia contemporană în proporții diferite. Din perspectivă diacronică, oiconimele sunt legate de mănăstiri, de hramul unor biserici, de slujitori ai cultelor, de diverse obiecte și practici religioase. Prin urmare, au o motivare obiectivă prin reperul referențial direct și oferă date importante despre istoria și tradițiile dintr-o regiune. În Transilvania, denumirile cu caracter religios confirmă coexistența ortodoxiei și a catolicismului, cu aspect românesc, slav, maghiar sau german, în funcție de etniile conlocuitoare.

Numele cu conotație sacră ocupă un procent mult mai mic în peisajul hodonimic actual, întrucât autoritățile administrative locale consideră că trebuie acordată prioritate aspectelor culturale, naționale, politice, sociale și etnice, în actul de numire a căilor de comunicație. În perioada comunistă s-a recurs la ștergerea oricăror urme de religiozitate din inventarul stradal românesc, însă, după anul 1989, au reînceput să apară denumiri religioase fie motivate geografic, prin reperul sacru deținut (o biserică, mănăstire, catedrală), fie în concordanță cu configurația confesională a localității sau ca evocare a memoriei unor sfinți, martiri, prelați originari din arealul respectiv sau care și-au desfășurat activitatea pastorală în respectivele orașe.

\section{Bibliografie}

Bőlcskei, A. 2013. Contemporary Hungarian settlement names reflecting former ecclesiastical possession. În Proceedings of the Second International Conference on Onomastics "Name and Naming". Onomastics in Contemporary Public Space, O. Felecan (ed.), 243-253. Cluj-Napoca: Mega, Argonaut..

Bolocan, G., E. Șodolescu Silvestru, I. Burci, I. Toma 2009. Dicționarul entopic al limbii române, vol. I-II (DELR). Craiova: Universitaria.

Felecan, D. 2017. Nume de botez - între sacru și profan. Abordare teoretică. În Proceedings of the Fourth International Conference on Onomastics "Name and Naming". Sacred and Profane in Onomastics, O.Felecan (ed.), 19-34. Cluj-Napoca: Editura Mega, Editura Argonaut. 
Felecan, O. 2013a. Anthroponyms en odonymie (aspects théoriques). Nouvelle Revue d'Onomastique (NRO) 55: 143-151.

Felecan, O. 2013b. Hodonimie românească - între autohtonism și cosmopolitism. În Proceedings of the Second International Conference on Onomastics "Name and Naming". Onomastics in Contemporary Public Space, Oliviu Felecan (ed.), 318-328. Cluj-Napoca: Editura Mega, Editura Argonaut.

Felecan, O. 2015. Borders and Ethnic Identities Reflected in Street Names from Transylvanian Localities. Transylvanian Review XXIV, Supplement nr. 1/ 2015, Regionalization in Globalization: 229-244.

Felecan, O. 2016. Un veac de transformări oiconimice în România. În Magistri et alumni, amore scribendi. Studia. In honorem Professoris Nicolae Felecan, O. Felecan, D. Felecan (coord.), 439453. Cluj-Napoca: Editura Mega, Editura Argonaut.

Felecan, O. 2017. Oikonymic Transformations in Romania in the Second Half of the Twentieth Century. Names 65 (2): 78-87.

Felecan, O., N. Felecan 2013. Cultural and linguistic layers embedded in Romanian oikonyms derived from hagionyms. Onoma 48: 89-107.

Frățilă, V. 2011. Oiconime bănățene de origine maghiară. În Confluențe lingvistice și filologice, O. Felecan și D. Felecan (coord.), 411-130. Cluj-Napoca: Editura Mega.

Goicu, S. 1999. Termeni creștini în onomastica românească. Timișoara: Editura Amphora.

Iordan, I., P. Gâștescu, D. I. Oancea 1974. Indicatorul localităților din România. București: Editura Academiei.

Mező, A. 1996. A templomcím a magyar helységnevekben. 11-15. Század [Patron saints in Hungarian settlement names. 11-15th c.]. Budapest: Magyar Egyháztörténeti Enciklopédia Munkaközösség.

Mező, A. 1997. Az „egyházi” helységneveink típusai [Types of Hungarian “ecclesiastical” settlement names]. In Az V. Magyar Névtudományi Konferenciaelöadásai: Vol.1, P. B. Gergely and M. Hajdú (eds.), 244-249. Budapest and Miskolc: Magyar Nyelvtudományi Társaságand Miskolci Egyetem Bölcsészettudományi Intézete.

Nicolae, I., B. Suditu 2008. Toponimie românească și internațională. București: Editura Meronia. Sala, M. (ed.) 1989. Enciclopedia limbilor romanice, Bucureşti: Editura Ştiinţifică și Enciclopedică. Sala, M. (ed.) 2001. Enciclopedia limbii române, Bucureşti: Editura Univers Enciclopedic.

Suciu, C. 1967, 1968. Dicționar istoric al localităților din Transilvania. Vol. I, II. București: Editura Academiei. 